\title{
Weibull-Exponential Distribution and Its Application in Monitoring Industrial Process
}

\author{
Muhammad Bilal, ${ }^{1,2}$ Muhammad Mohsin, ${ }^{2}$ and Muhammad Aslam $\mathbb{D i D}^{3}$ \\ ${ }^{1}$ Department of Statistics and Computer Science, University of Veterinary and Animal Sciences, Lahore, Pakistan \\ ${ }^{2}$ Department of Statistics, COMSATS University Islamabad, Lahore Campus, Lahore 54000, Pakistan \\ ${ }^{3}$ Department of Statistics, Faculty of Science, King Abdulaziz University, Jeddah 21551, Saudi Arabia
}

Correspondence should be addressed to Muhammad Aslam; aslam_ravian@hotmail.com

Received 4 December 2020; Revised 12 February 2021; Accepted 6 March 2021; Published 26 March 2021

Academic Editor: Hussein Abulkasim

Copyright (C) 2021 Muhammad Bilal et al. This is an open access article distributed under the Creative Commons Attribution License, which permits unrestricted use, distribution, and reproduction in any medium, provided the original work is properly cited.

\begin{abstract}
This paper presents a new Weibull family of distributions. The compatibility of the newly developed class is justified through its application in the field of quality control using Weibull-exponential distribution, a special case of the proposed family. In this paper, an attribute control chart using Weibull-exponential distribution is developed. The estimations of the model parameters and the proposed chart parameters are performed through the methods of maximum likelihood and average run-length. The significance of the proposed model is demonstrated using a simulation study and real-life problems. The results of the monitoring process and quick detection are compared with exponential distribution.
\end{abstract}

\section{Introduction}

The Weibull (W) distribution is extensively used to model failure time data. Numerous distributions have been developed and applied to describe various phenomena in engineering and quality control. Several generalizations of the family of distribution have been studied in the last two decades. Eugene et al. [1] proposed a new beta generated family of distributions for skewed and bimodal data. Many practitioners discussed a technique to generate different distributions Nadarajah and Kotz [2], Nadarajah and Gupta [3], Nadarajah and Kotz [4], and Nadarajah et al. [5]. Alzaatreh et al. [6] generalized the technique of Eugene et al. [1] to develop distributions defined over any domain. A lot of work is available in the recent literature regarding Alzaatreh et al. [6], Cordeiro et al. [7], Afify et al. [8], Alizadeh et al. [9], Afify et al. [8, 10], and Nofal et al. [11]. Chahkandi and Ganjali [12] established an exponential power series (EPS) family of distributions, which included a new mixture of an exponential and binomial distribution (see Barreto-Souza et al. [13]). Lu and Shi [14] introduced the $\mathrm{W}$-geometric (WG) and W-Poisson (WP) distributions were expanded as exponential geometric and exponential Poisson distributions, respectively. A comprehensive account of statistical methods can be traced in quality control since its commencement. In 1924, Walter A. Shewhart developed the concept of statistical quality control [15]. In early days, the control charts were extensively applied to monitor production processes only, but nowadays these control charts are applied in various fields like health care [16], education [17], coal monitoring [18], nuclear engineering [17], and veterinary medicine $[19,20]$. Roberts [21] depicted a graphical technique to generate geometric moving average by selecting weight for most recent values. Brook and Evans [22] suggested the technique of adopting a Markov chain approach. By using this method, they attained a transition probability matrix along with moments, percentage points of run-length distribution, and exact probability of run-length. Lucas [23] developed a scheme by combining the Shewhart control chart with the cumulative sum control chart (CUSM), which detected the small shifts rapidly. Borror et al. [24] suggested the Markov chain approach to assess the average run-length (ARL). Khoo [25] designed a new approach to monitor the fraction of 
nonconforming products. They constructed a moving average (MA) control chart for a fraction of nonconforming using the ARL profile of simulation results and mathematical calculations.

Sukparungsee and Novikov [26] devolved analytical approximation of exponentially weighted moving average (EWMA) using a martingale procedure for the expectation of exit times. Areepong and Novikov [27] derived ARL and average delay time $(\mathrm{AD})$ utilizing the martingale approach. Noorossana et al. [28] worked on different methods to monitor rare health events utilizing the ZIB-EWMA chart. Santiago and Smith [29] put forward the idea of the probabilistic-based procedure to create a t-chart to observe the stability of the process. They yielded exponential distribution and defined supplementary rules like ARL and shift detection. Ho and Quinino [30] used the "np" control chart to monitor the process variability instead of the mean chart. They explored that the "np" control chart was better in performance than $R$ (range chart) and $S^{2}$ control chart. Aslam et al. [31] implemented an ordinary sampling plan and group sampling plan. They developed sampling plans for the multistage process, which depended upon time-truncated tests and gave nonlinear optimized solutions to decrease the average sample number. Rakitzis and Castagliola [32] studied the Shewhart control chart for zero-inflated probability models. They suggested pragmatic rules for the statistical design of inspected charts for a fixed sample size. Azam et al. [33] designed a control chart under a repetitive sampling technique using an exponential distribution. They analyzed two existing control charts with the new proposed chart using average run-length. Azam et al. [34] unfolded an attribute chart for the $\mathrm{W}$ distribution using the discriminant limits. They established a control chart to estimate parameters in light of ARL. Wu and Jiao [35] performed attribute inspection to track the mean value of variable characteristic for normal distribution. This chart produced an outof-control signal, if the interval between the two suspect samples is lower than a control limit. Kim and Lee [36] used a fixed sampling interval scheme (FSI) for the detection of small shifts to moderate shifts by increasing fractional parameters for zero-inflated binomial process. The effectiveness of the FSI scheme over the VSI (variable sampling interval) scheme was justified through a numerical study. For further achievements to the statistical process monitoring literature on the ShewhartCUSUM and Shewhart-EWMA, for instance, Aslam et al. [37] improved the GWMA (generally weighted moving average) monitoring scheme for the detection of large shift in the process. For this purpose, they proposed the phase-II composite Shewhart-GWMA scheme using the Mann-Whitney U statistic. Shah et al. [38] proposed a new monitoring scheme has been developed for time between events under exponential and gamma distribution. Shaheen et al. [39] developed a control chart using the lognormal distribution to monitor the variation under repetitive sampling scheme. Aslam et al. [40] developed and designed the modification of multiple dependent states' sampling plan for satisfying a mean lifetime of the products under Birnbaum-Saunders and Weibull distributions.

In modeling of real-data problems, the common failure time distribution needs not to be the same but can be a mixture of different lifetime distributions. Each of these distinct lifetime distributions can represent a different type of failure cause for the population, like weather change depending on different parameters such as temperature, humidity, wind flow, and precipitation. Each parameter follows different distributions, which together model the weather change. In this article, a new class of Weibull-G distributions is derived by using the method given by Alzaatreh et al. [6]. In fact, we follow a certain methodology, presented in equations (1) and (2). According to this methodology, we need $H(g(x))$ and $r(t)$, and for it, we use exponential and Weibull distributions. The exponential is a special case of Weibull distribution, but when we use the given methodology, the resulting distribution appears as the combination of exponential and Weibull distribution. Indeed, it is the combination of these two distributions, not the mixture of distributions. The benefit of using the proposed distribution is that it provides an extraparameter, which controls the kurtosis and provides better efficiency in detecting early shift. This can be seen from the comparison of proposed distribution with mere simple exponential and simple Weibull distributions. Thus, the four parameter distributions are more useful to explain several real-life phenomena much better than two or five parameters (see Berk et al. [41]). In quality control, this feature helps to detect out-of-control process much early.

We develop an attribute control chart scheme using WEx distribution. The parameter estimation of the WEx distribution is carried out through the maximum likelihood estimation method. The designed scheme is used to monitor the process out-of-control and found more suitable than existing schemes. We compare the results of the simulated data and real data of urinary tract infection in the health care department using the proposed scheme with the existing method based on ARL and control charts.

\section{Weibull-G Class of Distributions}

In this section, we derive the cumulative distribution function (cdf) and the probability density function (pdf) of the Weibull-G class of distributions. For this purpose, we use the method of Alzaatreh et al. [6]. The cdf of the proposed method is given as

$$
F(y)=\int_{a}^{H(G(x))} r(t) \mathrm{d} t,
$$

and the pdf is given as follows:

$$
f(x)=\left\{\frac{\mathrm{d}}{\mathrm{d} x} H(G(x))\right\} r(H(G(x))),
$$

where $r(t)$ is the pdf of the parent distribution and $H($. should satisfy the following conditions:

(i) $H(G(x)) \in[a, b]$.

(ii) $H(G(x))$ is differentiable and monotonically nondecreasing.

(iii) $H(G(x)) \longrightarrow a \quad$ as $\quad x \longrightarrow-\infty$, and $H(G(x)) \longrightarrow b$ as $x \longrightarrow \infty$. 
Using $H(G(x))=-\log \left[(1-G(x))^{\alpha}\right]$ and $r(t)$ of Weibull distribution, the cdf of the WG class of distributions is obtained as

$$
\begin{aligned}
F(x) & =\int_{a}^{-\log \left[(1-G(x))^{\alpha}\right]} \frac{c}{\gamma}\left(\frac{t}{\gamma}\right)^{c-1} \exp \left(-\left(\frac{t}{\gamma}\right)^{c}\right) \mathrm{d} t \\
& =1-\exp \left(-\left(\frac{-\log \left((1-G(x))^{\alpha}\right)}{\gamma}\right)^{c}\right),
\end{aligned}
$$

and pdf is obtained by differentiating (3) as

$$
\begin{aligned}
f(x)= & \alpha\left(\frac{c}{\gamma}\right)\left[\frac{-\log [1-G(x)]^{\alpha}}{\gamma}\right]^{c-1} \\
& \cdot e^{-\left[\left(-\log [1-G(x)]^{\alpha} / \gamma\right)\right]^{c}} \frac{g(x)}{1-G(x)} .
\end{aligned}
$$

Now, several new distributions can be generated for the different values of $G(x)$.

\section{Weibull-Exponential Distribution}

In this section, we derive Weibull-exponential distribution using the proposed class of distributions.

If $x$ is an exponential distribution with cdf and pdf, then it is

$$
\begin{aligned}
& G(x)=1-e^{-\lambda x}, \\
& g(x)=\lambda e^{-\lambda x},
\end{aligned}
$$

respectively. The cdf and the pdf of the WEx distribution is generated by inserting (5) and (6) in (3) as

$$
\begin{aligned}
& F(x)=1-e^{-(\alpha \lambda x / \gamma)^{c}}, \\
& f(x)=c\left(\frac{\alpha \lambda}{\gamma}\right)^{c} x^{c-1} e^{-(\alpha \lambda x / \gamma)^{c}}, \quad x>0, \alpha>0, \gamma, \lambda>0 .
\end{aligned}
$$

Some special cases of the proposed distribution are given in Appendix (Table 1).

\section{The Proposed Control Chart}

This article proposes the new scheme of attribute characteristics control charts for the manufacturing process using WEx distribution. For a fixed sampling interval, where $n$ is considered as a sample for each subgroup, we discuss the lifetime of the product when random variable follows the proposed model. If the selected unit falls within control limits, we accept it; otherwise, it would be rejected. Therefore, we present the lower control limit (LCL) and upper control limit (UCL) as follows.

The LCL and UCL are defined as

$$
\begin{gathered}
P_{r}\left(X<\mathrm{LCL} \mid c_{0}\right)=P_{L}, \\
P_{r}\left(X<\mathrm{UCL} \mid c_{0}\right)=P_{U},
\end{gathered}
$$

TABLE 1: Special cases of the proposed distribution.

\begin{tabular}{lcc}
\hline Special cases & Parameters & Distribution \\
\hline Case 1 & $(\alpha \lambda / \gamma)=\theta$ & $f(x) \sim W(\theta, c)$ \\
Case 2 & If $c=1, \lambda=1, \alpha=1$ & $f(x) \sim \operatorname{Exp}(\gamma)$ \\
Case 3 & If $\gamma=1, \lambda=1, \alpha=1$ & $f(x) \sim W(c)$ \\
Case 4 & If $c=1, \alpha=1$ & $f(x) \sim \operatorname{Exp}(\lambda, \gamma)$ \\
Case 5 & If $c=2$ & $f(x) \sim \operatorname{Rayleigh}(\alpha, \lambda, \gamma)$ \\
\hline
\end{tabular}

respectively, where $c_{0}$ is the shape parameter. The LCL and UCL for the control process by following Azam et al. [34] are given by

$$
\begin{aligned}
& \mathrm{LCL}=\frac{\gamma}{\alpha \lambda}\left[\ln \frac{1}{1-P_{L}}\right]^{(1 / c)}, \\
& \mathrm{UCL}=\frac{\gamma}{\alpha \lambda}\left[\ln \frac{1}{1-P_{U}}\right]^{(1 / c)} .
\end{aligned}
$$

Ho and Quinino [30] presented the derivation of control charts.

Firstly, a sample is chosen at random from each subgroup and its quality characteristics $X$ are measured. The selected unit is accepted if it lies within defined limits and otherwise declared as rejected.

Secondly, the process is in control if $a$ item is accepted at first and out-of-control if $b$ item is rejected first.

When the process is in control, the probability that the process is out-of-control is defined as

$$
P_{0}=P\left(\operatorname{LCL}<X<\mathrm{UCL} \mid c=c_{0}\right)=1-P_{U}+P_{L} .
$$

Moreover, for the in-control process, the probability of the out-of-control process is demonstrated through control charts is given as

$$
P_{\mathrm{out}}^{0}=1-\sum_{x=a}^{a+b-1}\left(\begin{array}{c}
x-1 \\
a-1
\end{array}\right) P_{o}^{a}\left(1-P_{0}\right)^{x-a} .
$$

Furthermore, the shape parameter is converted to $c_{1}$. Then, the probability of the rejected item is derived as

$$
P_{1}=P\left(\mathrm{LCL}<X<\mathrm{UCL} \mid c=c_{1}\right) .
$$

The probability that the process is found to be out-ofcontrol due to the shifted process using control chart is obtained as

$$
P_{\text {out }}^{1}=1-\sum_{x=a}^{a+b-1}\left(\begin{array}{c}
x-1 \\
a-1
\end{array}\right) P_{1}^{a}\left(1-P_{1}\right)^{x-a} .
$$

Now, the shape parameter is considered for the shifted process, which is given as follows:

$$
c=f * c_{1},
$$

where $f$ is a shifted constant and lies between 0.25 and 1 . Therefore, (11) is formed as 


$$
\begin{aligned}
& P_{1}=\exp \left[\left(\frac{\alpha \lambda \mathrm{UCL}}{\gamma}\right)^{f c_{1}}\right]+1-\exp \left[\left(\frac{\alpha \lambda \mathrm{LCL}}{\gamma}\right)^{f c_{1}}\right], \\
& P_{1}=1+\exp \left[-\left(\frac{\alpha \lambda}{\gamma} * \frac{\gamma}{\alpha \lambda}\right)\left(\left(\ln \frac{1}{1-P_{U}}\right)^{\frac{1}{c_{1}}}\right)^{f c_{1}}\right]-\exp \left[-\left(\frac{\alpha \lambda}{\gamma} * \frac{\gamma}{\alpha \lambda}\right)\left(\left(\ln \frac{1}{1-P_{L}}\right)^{\left(1 / c_{1}\right)}\right)^{f c_{1}}\right], \\
& P_{1}=1+\exp \left[-\ln \left(\frac{1}{1-P_{U}}\right)^{f}\right]-\exp \left[-\ln \left(\frac{1}{1-P_{L}}\right)^{f}\right] .
\end{aligned}
$$

The ARL is evaluated using $P_{0}$ and $P_{1}$ which are obtained through the parameters of the proposed distribution. Note here that, the equations of $P_{0}$ and $P_{1}$ are independent of scale parameters. Therefore, we fixed only the shape parameter.

Now, the ARL of in-control and ARL of out-of-control have been calculated as

$$
\mathrm{ARL}_{0}=\frac{1}{P_{\text {out }}^{0}} \text { and } \mathrm{ARL}_{1}=\frac{1}{P_{\text {out }}^{1}} .
$$

\section{ARL Behavior of the Newly Proposed Control Chart}

In this section, we discuss the ARL behavior of the suggested control chart. A simulation study is conducted in the R-language program using the above-estimated equations of probabilities. In simulation study, 10,000 samples are generated from the well-known exponential, Weibull, and the proposed WEx distributions. The ML estimates of the parameters of the suggested distribution are obtained by using SANN (simulated annealing) given in Belisle [42]. SANN is an optimization technique, which is more recent and flexible as compared to Newton-Raphson. The SANN method is available in R-package maxLik Henningsen and Toomet [43]. We fixed the shape parameters to find the ARLs.

These ML estimates are used to find ARLs for $\mathrm{ARL}_{0}=200,300$, and 370. Furthermore, ARLvalues are explained by calculating for different drift levels. It is important to mention that the shift unit is equal to the incontrol ARL. The performance of ARL can be understood by reading the R-code program. Simulated data of 10,000 samples are generated by choosing the random values of $a, b$, and $n$. For in-control processes, the ARL is calculated by using these given random values. For the selection of $a$ and $b$ parameters, see details in Ho and Quinino [30]. Moreover, we compare the exponential and Weibull distribution with the proposed WEx distribution for the efficiency of ARL.

\section{Comparative Study}

In this section, we compare the performance of the proposed WEx distribution with the exponential distribution under ARL. In Table 2, we report the estimated values of the proposed model parameters. Various values of the parameters of exponential, Weibull, and the proposed WEx distributions are placed in Tables 3-5 for various combinations of $a$ and $b$ at $\mathrm{ARL}_{0}=200,300$, and 370. From Table 3, it is seen that various values of $a$ and $b$ at $f=1$, i.e., there is no shift in the values of ARLs of the exponential, Weibull, and the proposed WEx distributions, are the same; i.e., 201.98, 303.33, and 371.99 at $\mathrm{ARL}_{0}=200,300$, and 370. On the other hand, it is observed that, at a different shift level $f=1$ to 0.25 , the values of ARL decrease for the exponential and the proposed models.

One can clearly observe in Tables 3-5 that the proposed model suppressed the exponential and Weibull distribution in terms of shift detection. From Table 3, for instance, the value of ARL is 17.04 for the WEx distribution and 65.5 for the exponential distribution when $f=0.85, a=9, b=20$, and $\mathrm{ARL}_{0}=200$. Furthermore, Tables 4 and 5 also represent the values of ARLs of the exponential and the proposed models at $\mathrm{ARL}_{0}=200,300$, and 370 with $P_{L}=0.1$ and $P_{U}=0.9$ and $P_{L}=0.2$ and $P_{U}=$ 0.8 for various combinations of $a$ and $b$ at different levels of shifts. It can be noticed that the values of ARLs decrease for both models when the values of $a$ and $b$ decrease. By comparing both models, it is concluded that the proposed model gives quick detection of out-ofcontrol process at different levels of shifts. Tables 4 and 5 are presented in Appendix.

Figures 1-9 demonstrate the graphical representations of the performance of ARLs at 200,300, and 370 for several combinations of $a \& b$ and $P_{L} \& P_{U}$. One can see from Figures 1-9 as shift level $f$ decreases the curves of ARLs, the exponential and the proposed WEx distributions also decrease. Also, the ARL curves show that the behavior of the proposed model is better than that of the compared model. Figures 4-9 are also presented in Appendix.

\section{Real-Life Example}

In this section, the proposed control chart is implemented in real-life data set from the health sector. The data of urinary tract infection (UTI) are taken from the hospital system. These data are attained from Azam et al. [34] which was initially used by Santiago and Smith [29]. Data are collected from a hospital with a high risk of urinary tract infections particularly to identify risk rate 
TABLe 2: Maximum likelihood estimation of the proposed WEx distribution parameter.

Maximum likelihood estimation

SANN maximization, 10000 iterations

Return code: 0 successful convergence

Log-likelihood: -42.88574

\begin{tabular}{lcccc}
\hline Parameter estimates & Estimate & Std. error & $t$ value & $P$ value \\
\hline$\alpha$ & 2.74 & 0.06969 & 39.3169 & $2 e-16$ \\
\hline C & 1.328 & 4.4492 & 0.29484 & 0.653 \\
\hline$\gamma$ & 7.01 & 7.1518 & 0.9801 & 0.613 \\
\hline$\lambda$ & 4.88 & 11.3607 & 0.4293 & 0.697 \\
\hline
\end{tabular}

TABLE 3: Comparison of ARL (SDRL) using exponential and Weibull distributions and WEx distribution with $p_{L}=0.05$ and $p_{U}=0.95$.

\begin{tabular}{|c|c|c|c|c|c|c|c|c|c|}
\hline \multirow[t]{2}{*}{$f$} & \multicolumn{3}{|c|}{$\begin{array}{l}\mathrm{ARL}_{0}=200 \\
a=9, b=20\end{array}$} & \multicolumn{3}{|c|}{$\begin{array}{l}\mathrm{ARL}_{0}=300 \\
a=7, b=10\end{array}$} & \multicolumn{3}{|c|}{$\begin{array}{c}\mathrm{ARL}_{0}=370 \\
a=13, b=37\end{array}$} \\
\hline & Exp & Weibull & WEx & Exp & Weibull & WEx & Exp & Weibull & WEx \\
\hline 1 & $\begin{array}{c}201.98 \\
(201.48) \\
\end{array}$ & $\begin{array}{c}201.98 \\
(201.48) \\
\end{array}$ & $\begin{array}{c}201.98 \\
(201.48) \\
\end{array}$ & $\begin{array}{c}303.33 \\
(302.83) \\
\end{array}$ & $\begin{array}{c}303.33 \\
(302.83) \\
\end{array}$ & $\begin{array}{c}303.33 \\
(302.83) \\
\end{array}$ & $\begin{array}{c}371.99 \\
(371.49) \\
\end{array}$ & $\begin{array}{c}371.99 \\
(371.49) \\
\end{array}$ & $\begin{array}{c}371.99 \\
(371.49) \\
\end{array}$ \\
\hline 0.99 & $\begin{array}{c}189.71 \\
(189.21) \\
\end{array}$ & $\begin{array}{c}228.04 \\
(227.54) \\
\end{array}$ & $\begin{array}{c}167.50 \\
(166.99) \\
\end{array}$ & $\begin{array}{c}287.91 \\
(287.41) \\
\end{array}$ & $\begin{array}{c}335.52 \\
(335.02) \\
\end{array}$ & $\begin{array}{c}259.48 \\
(258.98) \\
\end{array}$ & $\begin{array}{c}341.46 \\
(340.96) \\
\end{array}$ & $\begin{array}{c}439.25 \\
(438.75)\end{array}$ & $\begin{array}{c}288.13 \\
(287.62) \\
\end{array}$ \\
\hline 0.95 & $\begin{array}{c}144.93 \\
(144.43) \\
\end{array}$ & $\begin{array}{c}351.89 \\
(351.39) \\
\end{array}$ & $81.72(81.22)$ & $\begin{array}{c}229.87 \\
(229.37) \\
\end{array}$ & $\begin{array}{c}480.20 \\
(479.70) \\
\end{array}$ & $\begin{array}{c}141.65 \\
(141.15) \\
\end{array}$ & $\begin{array}{c}236.66 \\
(236.16) \\
\end{array}$ & $\begin{array}{c}798.29 \\
(797.79) \\
\end{array}$ & $\begin{array}{c}109.4 \\
(108.90) \\
\end{array}$ \\
\hline 0.9 & $\begin{array}{c}99.43 \\
(98.93) \\
\end{array}$ & $\begin{array}{c}513.59 \\
(513.09) \\
\end{array}$ & $\begin{array}{c}35.81 \\
(35.30) \\
\end{array}$ & $\begin{array}{c}167.32 \\
(166.82) \\
\end{array}$ & $\begin{array}{l}(654.78) \\
(654.28) \\
\end{array}$ & $\begin{array}{c}69.45 \\
(68.95) \\
\end{array}$ & $\begin{array}{c}142.27 \\
(141.77) \\
\end{array}$ & $\begin{array}{c}1348.95 \\
(1348.45)\end{array}$ & $36.91(36.41)$ \\
\hline 0.85 & 65.5 (64.99) & $\begin{array}{c}586.54 \\
(586.04)\end{array}$ & $\begin{array}{c}17.04 \\
(16.54)\end{array}$ & $\begin{array}{c}117.23 \\
(116.73)\end{array}$ & $\begin{array}{c}729.78 \\
(729.28)\end{array}$ & $35.81(35.30)$ & $\begin{array}{c}81.49 \\
(80.99)\end{array}$ & $\begin{array}{c}1623.17 \\
(1622.66)\end{array}$ & $14.37(13.86)$ \\
\hline 0.8 & $41.7(41.20)$ & $\begin{array}{c}507.34 \\
(506.84)\end{array}$ & $8.84(8.32)$ & $\begin{array}{c}79.35 \\
(78.85) \\
\end{array}$ & $\begin{array}{c}648.25 \\
(647.75)\end{array}$ & $19.44(18.94)$ & $\begin{array}{c}45.00 \\
(44.49)\end{array}$ & $\begin{array}{c}1326.14 \\
(1325.64)\end{array}$ & $6.49(5.97)$ \\
\hline 0.75 & $\begin{array}{c}25.88 \\
(25.38)\end{array}$ & $\begin{array}{c}337.90 \\
(337.40)\end{array}$ & $5.01(4.48)$ & $52.14(51.63)$ & $\begin{array}{c}464.42 \\
(463.92)\end{array}$ & $11.14(10.63)$ & $\begin{array}{c}24.32 \\
(23.82)\end{array}$ & $\begin{array}{c}754.76 \\
(754.26)\end{array}$ & $3.41(2.87)$ \\
\hline 0.7 & $\begin{array}{c}15.83 \\
(15.32) \\
\end{array}$ & $\begin{array}{c}183.37 \\
(182.87) \\
\end{array}$ & $3.11(2.56)$ & $\begin{array}{c}33.47 \\
(32.97) \\
\end{array}$ & $\begin{array}{c}279.86 \\
(279.36) \\
\end{array}$ & $6.74(6.22)$ & $13.11(12.60)$ & $\begin{array}{c}325.98 \\
(325.47) \\
\end{array}$ & $2.09(1.51)$ \\
\hline 0.65 & $9.66(9.15)$ & $87.14(86.64)$ & $2.12(1.54)$ & $21.15(20.65)$ & $\begin{array}{c}149.60 \\
(149.10) \\
\end{array}$ & $4.33(3.79)$ & $7.21(6.69)$ & $\begin{array}{c}119.20 \\
(118.70) \\
\end{array}$ & $1.48(0.838)$ \\
\hline 0.6 & $5.97(5.45)$ & $\begin{array}{c}38.70 \\
(38.20) \\
\end{array}$ & $1.58(0.953)$ & $13.28(12.77)$ & $74.35(73.84)$ & $2.94(2.39)$ & $4.14(3.60)$ & $40.83(40.33)$ & $1.19(0.476)$ \\
\hline 0.55 & $3.80(3.26)$ & 16.89 (16.39) & $1.28(0.599)$ & $8.37(7.85)$ & $35.52(35.02)$ & $2.13(1.55)$ & $2.55(1.99)$ & $14.22(13.71)$ & $1.06(0.259)$ \\
\hline 0.5 & $2.53(1.97)$ & $7.54(7.02)$ & $1.12(0.371)$ & $5.35(4.82)$ & $16.70(16.19)$ & $1.64(1.03)$ & $1.72(1.12)$ & $5.40(4.87)$ & $1.02(1.13)$ \\
\hline 0.25 & $1.01(0.098)$ & $\begin{array}{c}1.001 \\
(0.0296)\end{array}$ & $1(0.005)$ & $1.15(0.409)$ & $1.04(0.211)$ & $1(0.082)$ & $1(0.012)$ & $1.00(0.0013)$ & $1(0.00004)$ \\
\hline
\end{tabular}

and the frequency of the UTI patients being discharged. In this example, male patients are focused. The data show the number of days between admissions and discharge of the patients having UTIs. The simulated data for the above scenario are generated from the proposed WEx distribution with $P_{L}=0.1, P_{U}=0.9, a=29$, and $b=59$. Firstly, we generate 40 observations for the in-control process and then the next 40 observations for the shifted process with $f=0.90$, as presented in Tables 6 and 7 . In addition, we estimate the values of LCL and UCL as 0.03206 and 0.95051 , respectively, and display in Figure 10. Figures 10 and 11 show the LCL and UCL for incontrol and out-of-control data. It is clearly shown that 40th value is detected as out-of-control for the proposed model.

\section{Comparisons of the Exponential and the Weibull-Exponential Distribution Using Real-Life Example}

In this section, we compare the control charts of the exponential and the proposed WEx distributions using real data of UTI patients. It can be easily seen in Figure 12 that the control chart of the exponential distribution is in-control and no value is detected as out-of-control, 
TABLE 4: Comparison of ARL (SDRL) using exponential and Weibull distributions and WEx distribution with $\mathbf{p}_{\mathbf{L}}=0.1$ and $\mathbf{p}_{\mathbf{U}}=0.9$

\begin{tabular}{|c|c|c|c|c|c|c|c|c|c|}
\hline \multirow[t]{2}{*}{$f$} & \multicolumn{3}{|c|}{$\begin{array}{c}\mathrm{ARL}_{0}=200 \\
a=29, b=59\end{array}$} & \multicolumn{3}{|c|}{$\begin{array}{c}\mathrm{ARL}_{0}=300 \\
a=23, b=40\end{array}$} & \multicolumn{3}{|c|}{$\begin{array}{c}\mathrm{ARL}_{0}=370 \\
a=34, b=70\end{array}$} \\
\hline & Exp & Weibull & WEx & Exp & Weibull & WEx & Exp & Weibull & WEx \\
\hline 1 & $\begin{array}{c}200.01 \\
(199.51)\end{array}$ & $\begin{array}{c}200.01 \\
(199.51) \\
\end{array}$ & $\begin{array}{c}200.01 \\
(199.51) \\
\end{array}$ & $\begin{array}{c}304.99 \\
(304.49)\end{array}$ & $\begin{array}{c}304.99 \\
(304.49) \\
\end{array}$ & $\begin{array}{c}304.99 \\
(304.49)\end{array}$ & $\begin{array}{c}374.91 \\
(374.41)\end{array}$ & $\begin{array}{c}374.91 \\
(374.41)\end{array}$ & $\begin{array}{c}374.91 \\
(374.41)\end{array}$ \\
\hline 0.99 & $\begin{array}{c}181.27 \\
(180.77) \\
\end{array}$ & $\begin{array}{c}242.46 \\
(241.96) \\
\end{array}$ & $\begin{array}{c}150.1 \\
(149.60) \\
\end{array}$ & $\begin{array}{c}279.28 \\
(278.78) \\
\end{array}$ & $\begin{array}{r}362.15 \\
(361.65) \\
\end{array}$ & $\begin{array}{c}235.77 \\
(235.27) \\
\end{array}$ & $\begin{array}{c}334.49 \\
(333.99) \\
\end{array}$ & $\begin{array}{c}468.70 \\
(468.20) \\
\end{array}$ & $\begin{array}{c}268.78 \\
(268.28) \\
\end{array}$ \\
\hline 0.95 & $\begin{array}{c}119.61 \\
(119.11)\end{array}$ & $\begin{array}{c}494.23 \\
(493.76) \\
\end{array}$ & $\begin{array}{c}51.55 \\
(51.05) \\
\end{array}$ & $\begin{array}{c}192.14 \\
(191.64) \\
\end{array}$ & $\begin{array}{c}680.54 \\
(680.03) \\
\end{array}$ & $89.12(88.62)$ & $\begin{array}{c}206.62 \\
(206.12) \\
\end{array}$ & $\begin{array}{c}1071.88 \\
(1071.38) \\
\end{array}$ & $\begin{array}{l}78.115 \\
(77.61) \\
\end{array}$ \\
\hline 0.9 & $\begin{array}{c}68.05 \\
(67.55) \\
\end{array}$ & $\begin{array}{c}967.05 \\
(966.52) \\
\end{array}$ & $\begin{array}{c}16.29 \\
(15.78) \\
\end{array}$ & $\begin{array}{c}115.04 \\
(114.54)\end{array}$ & $\begin{array}{c}1225.84 \\
(1225.34)\end{array}$ & $30.13(29.62)$ & $\begin{array}{c}107.63 \\
(107.13) \\
\end{array}$ & $\begin{array}{c}2340.44 \\
(2339.94) \\
\end{array}$ & $\begin{array}{c}20.78 \\
(20.28) \\
\end{array}$ \\
\hline 0.85 & $37.3(36.79)$ & $\begin{array}{c}1294.41 \\
(1293.91)\end{array}$ & $6.35(5.83)$ & $\begin{array}{c}66.01 \\
(65.51) \\
\end{array}$ & $\begin{array}{c}1580.35 \\
(1579.85) \\
\end{array}$ & $11.85(11.34)$ & $\begin{array}{c}53.79 \\
(53.29) \\
\end{array}$ & $\begin{array}{c}3286.59 \\
(3286.09) \\
\end{array}$ & $7.12(6.60)$ \\
\hline 0.8 & $\begin{array}{c}20.02 \\
(19.51) \\
\end{array}$ & $\begin{array}{c}1062.93 \\
(1062.43)\end{array}$ & $3.06(2.51)$ & $\begin{array}{c}36.71 \\
(36.20) \\
\end{array}$ & $\begin{array}{c}1331.21 \\
(1330.71)\end{array}$ & $5.45(4.92)$ & $\begin{array}{c}26.31 \\
(25.81)\end{array}$ & $\begin{array}{c}2612.75 \\
(2612.25)\end{array}$ & $3.15(2.60)$ \\
\hline 0.75 & $\begin{array}{c}10.74 \\
(10.23) \\
\end{array}$ & $\begin{array}{c}522.02 \\
(521.52) \\
\end{array}$ & $1.82(1.22)$ & $\begin{array}{c}20.08 \\
(19.57) \\
\end{array}$ & $\begin{array}{c}714.11 \\
(713.61) \\
\end{array}$ & $2.94(2.39)$ & $\begin{array}{c}12.91 \\
(12.40) \\
\end{array}$ & $\begin{array}{c}1142.25 \\
(1141.75) \\
\end{array}$ & 1.79 (1.18) \\
\hline 0.7 & $5.90(5.38)$ & $\begin{array}{c}166.63 \\
(166.13) \\
\end{array}$ & $1.31(0.633)$ & $\begin{array}{c}11.00 \\
(10.48) \\
\end{array}$ & $\begin{array}{c}258.97 \\
(258.47) \\
\end{array}$ & $1.86(1.26)$ & $6.55(6.03)$ & $\begin{array}{c}303.37 \\
(302.87) \\
\end{array}$ & $1.27(0.583)$ \\
\hline 0.65 & $3.42(2.88)$ & $41.37(40.87)$ & $1.1(0.328)$ & $6.16(5.64)$ & $72.69(72.19)$ & $1.36(0.702)$ & $3.56(3.02)$ & $60.61(60.11)$ & $1.08(0.284)$ \\
\hline 0.6 & $2.15(1.57)$ & $10.09(9.58)$ & $1.02(0.155)$ & $3.62(3.08)$ & $18.88(18.38)$ & $1.14(0.392)$ & $2.14(1.56)$ & $12.03(11.52)$ & $1.01(0.122)$ \\
\hline 0.55 & $1.51(0.872)$ & $3.07(2.53)$ & $1(0.061)$ & $2.29(1.72)$ & $5.47(4.95)$ & $1.04(0.206)$ & $\begin{array}{c}1.46 \\
(0.8244) \\
\end{array}$ & $3.16(2.61)$ & $1(0.041)$ \\
\hline 0.5 & $1.19(0.476)$ & $1.42(0.770)$ & $1(0.018)$ & $\begin{array}{c}1.59 \\
(0.9692) \\
\end{array}$ & $2.10(1.520)$ & $1.01(0.095)$ & $\begin{array}{c}1.16 \\
(0.4275) \\
\end{array}$ & $1.38(0.7208)$ & $1(0.010)$ \\
\hline 0.25 & $1(0.0004)$ & $1.00(---)$ & $1(0.000)$ & $1(0.0079)$ & $\begin{array}{c}1.00 \\
(0.000001)\end{array}$ & $1(0.00002)$ & $1(0.0001)$ & $1.00(0.00000)$ & $1(0.000)$ \\
\hline
\end{tabular}

TABle 5: Comparison of ARLs (SDRL) using exponential and Weibull distribution and WEx distribution with $\mathbf{p}_{\mathbf{L}}=0.2$ and $\mathbf{p}_{\mathbf{U}}=0.8$.

\begin{tabular}{|c|c|c|c|c|c|c|c|c|c|}
\hline \multirow[t]{2}{*}{$f$} & \multicolumn{3}{|c|}{$\begin{array}{c}\mathrm{ARL}_{0}=200 \\
a=63, b=57\end{array}$} & \multicolumn{3}{|c|}{$\begin{array}{c}\mathrm{ARL}_{0}=300 \\
a=54, b=45\end{array}$} & \multicolumn{3}{|c|}{$\begin{array}{c}\mathrm{ARL}_{0}=370 \\
a=42, b=31\end{array}$} \\
\hline & Exp & Weibull & WEx & Exp & Weibull & WEx & Exp & Weibull & WEx \\
\hline 1 & $\begin{array}{c}200.21 \\
(199.71) \\
\end{array}$ & $\begin{array}{c}200.21 \\
(199.71) \\
\end{array}$ & $\begin{array}{c}200.21 \\
(119.71) \\
\end{array}$ & $\begin{array}{c}300.51 \\
(300.01) \\
\end{array}$ & $\begin{array}{c}300.51 \\
(300.01) \\
\end{array}$ & $\begin{array}{c}300.51 \\
(300.01) \\
\end{array}$ & $\begin{array}{c}370.82 \\
(370.32) \\
\end{array}$ & $\begin{array}{c}370.82 \\
(370.32) \\
\end{array}$ & $\begin{array}{c}370.82 \\
(370.32) \\
\end{array}$ \\
\hline 0.99 & $\begin{array}{c}182.13 \\
(181.63) \\
\end{array}$ & $\begin{array}{c}241.05 \\
(240.55) \\
\end{array}$ & $\begin{array}{c}152.62 \\
(152.12) \\
\end{array}$ & $\begin{array}{c}274.70 \\
(274.20)\end{array}$ & $\begin{array}{c}358.29 \\
(357.78)\end{array}$ & $\begin{array}{c}232.2 \\
(231.70) \\
\end{array}$ & $\begin{array}{c}342.73 \\
(342.23) \\
\end{array}$ & $\begin{array}{c}432.55 \\
(432.05) \\
\end{array}$ & $\begin{array}{c}295.64 \\
(295.14) \\
\end{array}$ \\
\hline 0.95 & $\begin{array}{c}122.3 \\
(121.80) \\
\end{array}$ & $\begin{array}{c}483.80 \\
(483.30) \\
\end{array}$ & $\begin{array}{c}55.17 \\
(54.67) \\
\end{array}$ & & $\begin{array}{c}690.67 \\
(690.17) \\
\end{array}$ & $\begin{array}{r}87.45 \\
(86.95) \\
\end{array}$ & $\begin{array}{c}245.41 \\
(244.91) \\
\end{array}$ & $\begin{array}{c}765.86 \\
(765.35) \\
\end{array}$ & $\begin{array}{c}124.17 \\
(123.67) \\
\end{array}$ \\
\hline 0.9 & $\begin{array}{c}71.44 \\
(70.94) \\
\end{array}$ & $\begin{array}{c}961.52 \\
(961.02) \\
\end{array}$ & $\begin{array}{c}18.14 \\
(17.63) \\
\end{array}$ & & $\begin{array}{c}1312.93 \\
(1312.43) \\
\end{array}$ & $\begin{array}{c}29.35 \\
(28.84) \\
\end{array}$ & & $\begin{array}{c}1333.46 \\
(1332.96) \\
\end{array}$ & $\begin{array}{c}45.98 \\
(45.48) \\
\end{array}$ \\
\hline 0.85 & $40.3(39.80)$ & $\begin{array}{c}1357.57 \\
(1357.07) \\
\end{array}$ & $7.18(6.66)$ & $\begin{array}{c}64.44 \\
(63.94) \\
\end{array}$ & $\begin{array}{c}1809.98 \\
(1809.48)\end{array}$ & $11.45(10.94)$ & $\begin{array}{c}94.33 \\
(93.83) \\
\end{array}$ & $\begin{array}{c}1756.73 \\
(1756.23) \\
\end{array}$ & $\begin{array}{c}18.96 \\
(18.45) \\
\end{array}$ \\
\hline 0.8 & $\begin{array}{c}22.24 \\
(21.74) \\
\end{array}$ & $\begin{array}{c}1181.92 \\
(1181.42)\end{array}$ & $3.44(2.90)$ & \begin{tabular}{|l|}
35.94 \\
$(35.44)$ \\
\end{tabular} & $\begin{array}{c}1591.17 \\
(1590.67)\end{array}$ & $5.24(4.71)$ & $\begin{array}{c}55.43 \\
(54.92) \\
\end{array}$ & $\begin{array}{c}1572.92 \\
(1572.42)\end{array}$ & $8.76(8.24)$ \\
\hline 0.75 & $\begin{array}{c}12.22 \\
(11.71) \\
\end{array}$ & $\begin{array}{c}578.96 \\
(578.46) \\
\end{array}$ & $2.00(1.41)$ & $\begin{array}{c}19.74 \\
(19.23) \\
\end{array}$ & $\begin{array}{c}817.31 \\
(816.81) \\
\end{array}$ & $2.82(2.27)$ & $\begin{array}{c}31.79 \\
(31.28) \\
\end{array}$ & $\begin{array}{c}886.02 \\
(885.52) \\
\end{array}$ & $4.56(4.03)$ \\
\hline 0.7 & $6.82(6.30)$ & $\begin{array}{c}162.28 \\
(161.77) \\
\end{array}$ & $1.39(0.740)$ & $\begin{array}{c}10.86 \\
(10.34) \\
\end{array}$ & $\begin{array}{c}246.16 \\
(245.66) \\
\end{array}$ & $1.79(1.19)$ & $\begin{array}{c}18.00 \\
(17.49)\end{array}$ & $\begin{array}{c}311.23 \\
(310.73)\end{array}$ & $2.69(2.13)$ \\
\hline 0.65 & $3.96(3.42)$ & $31.11(30.60)$ & $1.14(0.393)$ & $6.10(5.58)$ & $50.03(49.52)$ & $1.32(0.654)$ & $10.22(9.70)$ & $74.98(74.48)$ & $1.80(1.202)$ \\
\hline 0.6 & $2.45(1.89)$ & $5.83(5.31)$ & $1.04(0.195)$ & $3.59(3.05)$ & $9.22(8.71)$ & $1.12(0.358)$ & $5.92(5.39)$ & $15.37(14.86)$ & $1.36(0.702)$ \\
\hline 0.55 & $1.67(1.06)$ & $1.71(1.098)$ & $1.01(0.083)$ & $2.27(1.70)$ & $2.33(1.75)$ & $1.03(0.182)$ & $3.57(3.03)$ & $3.68(3.14)$ & $1.15(0.409)$ \\
\hline 0.5 & $1.27(0.589)$ & $1.05(0.2310)$ & $1(0.028)$ & $1.58(0.954)$ & $1.15(0.4118)$ & $1.01(0.079)$ & $2.29(1.72)$ & $1.44(0.7909)$ & $1.05(0.225)$ \\
\hline 0.25 & $1(0.0009)$ & $1.00(0.00000)$ & $1(0.0000)$ & $1(0.006)$ & $1.00(0.00000)$ & $1(0.00001)$ & $1(0.042)$ & $1.00(---)$ & $1(0.0004)$ \\
\hline
\end{tabular}




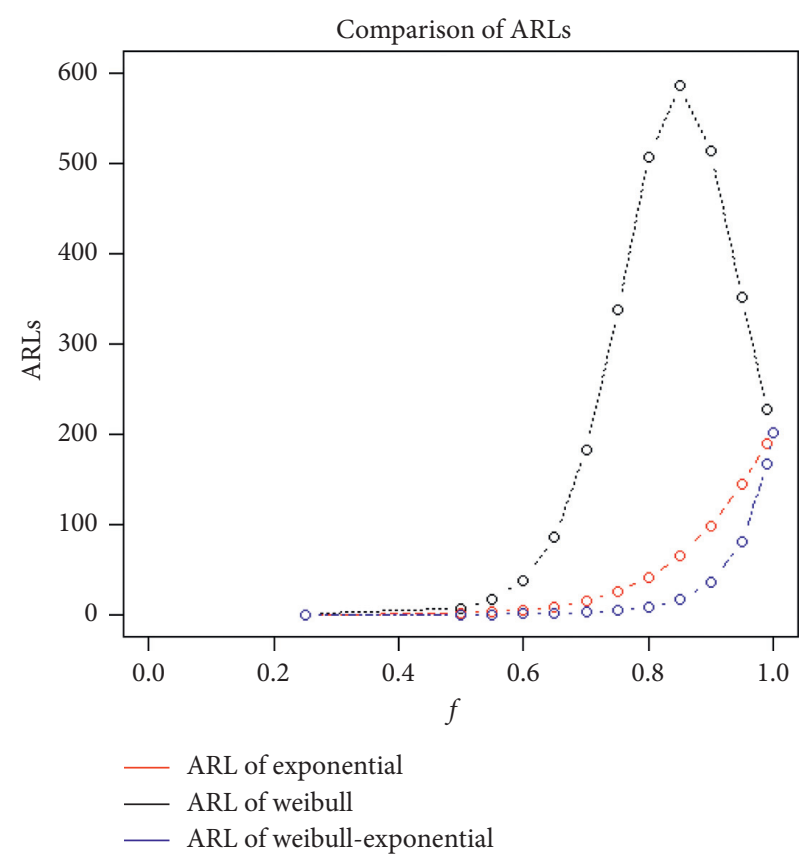

FIgURE 1: ARLs of exponential, Weibull, and proposed WEx at 200 with $\mathbf{p}_{\mathbf{L}}=0.05$ and $\mathbf{p}_{\mathbf{U}}=0.95$.

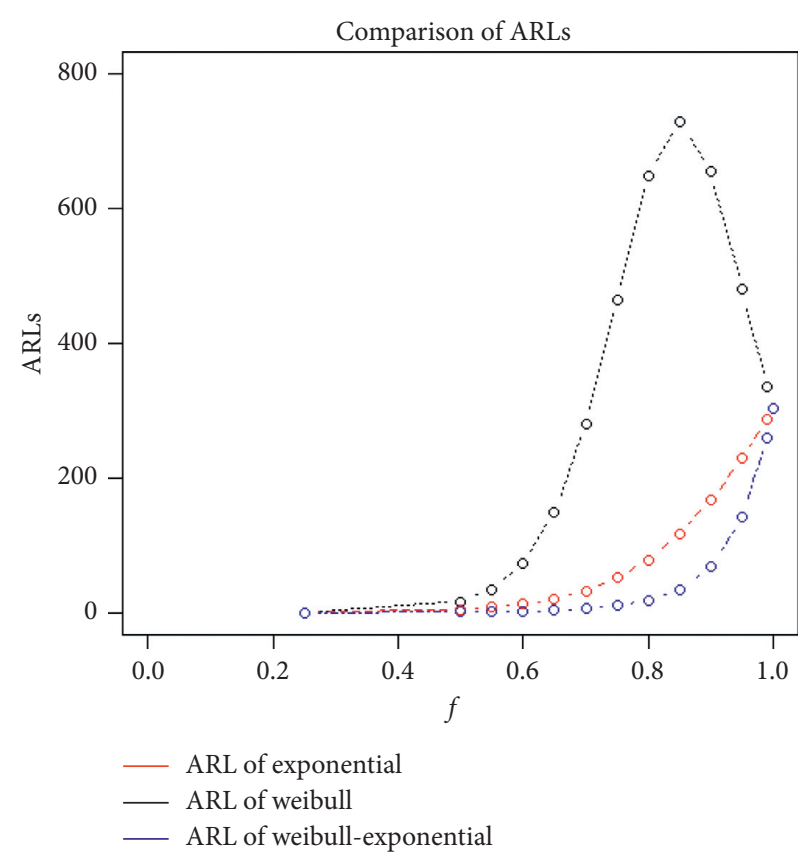

Figure 2: ARLs of exponential, Weibull, and proposed WEx at 300 with $p_{L}=0.05$ and $p_{U}=0.95$.

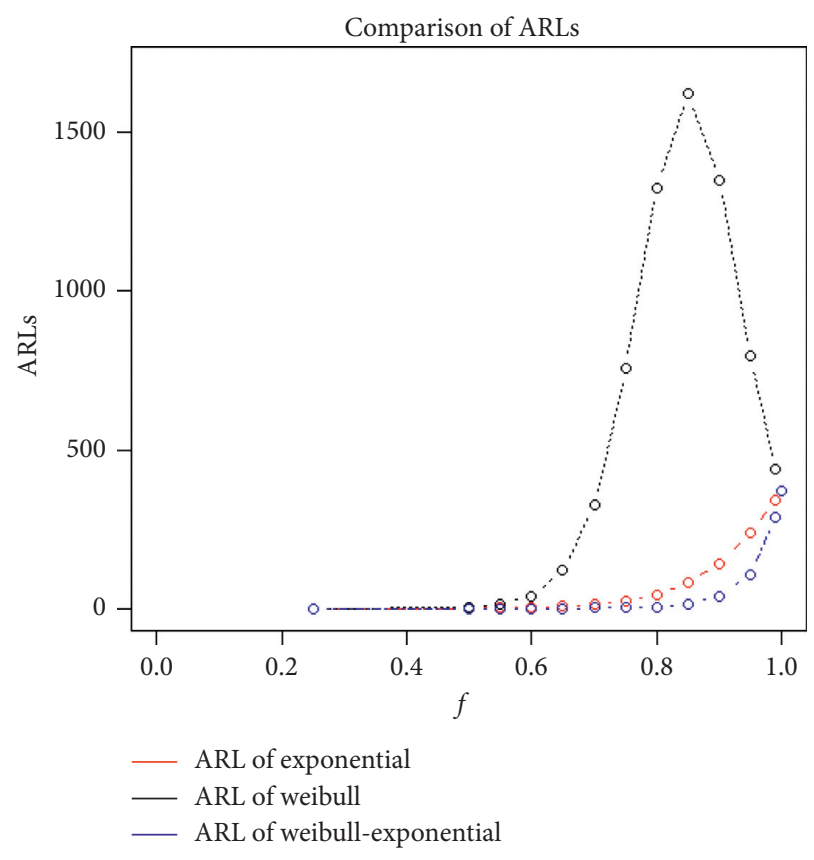

FIgURE 3: ARLs of exponential, Weibull, and proposed WEx at 370 with $\mathbf{p}_{\mathrm{L}}=0.05$ and $\mathbf{p}_{\mathrm{U}}=0.95$.

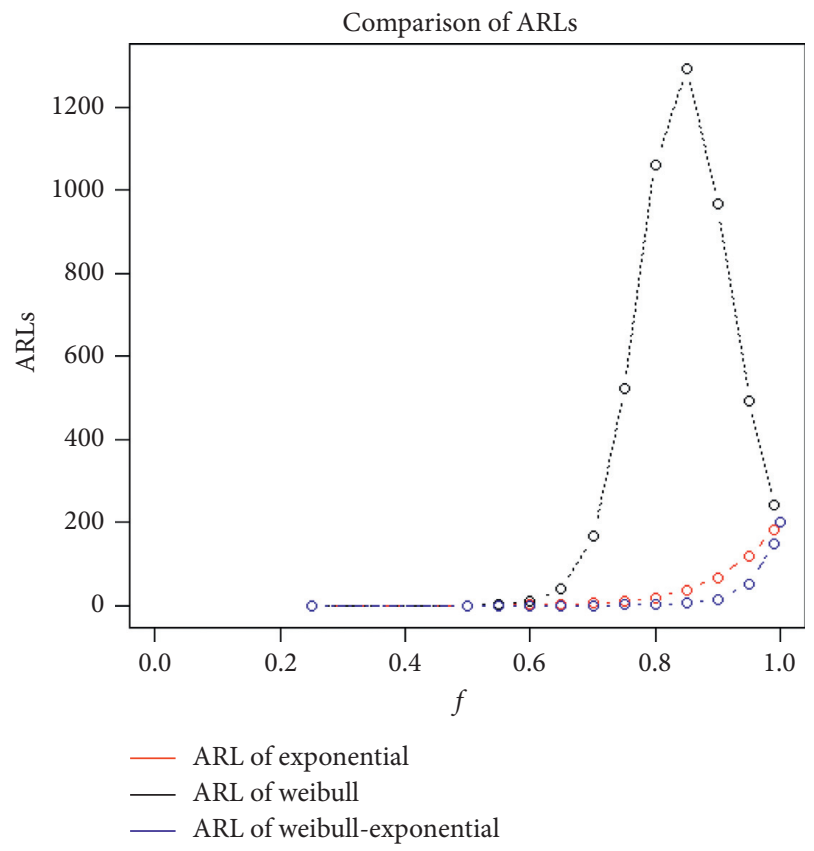

Figure 4: ARLs of exponential, Weibull, and proposed WEx at 200 with $p_{L}=0.1$ and $p_{U}=0.9$. 


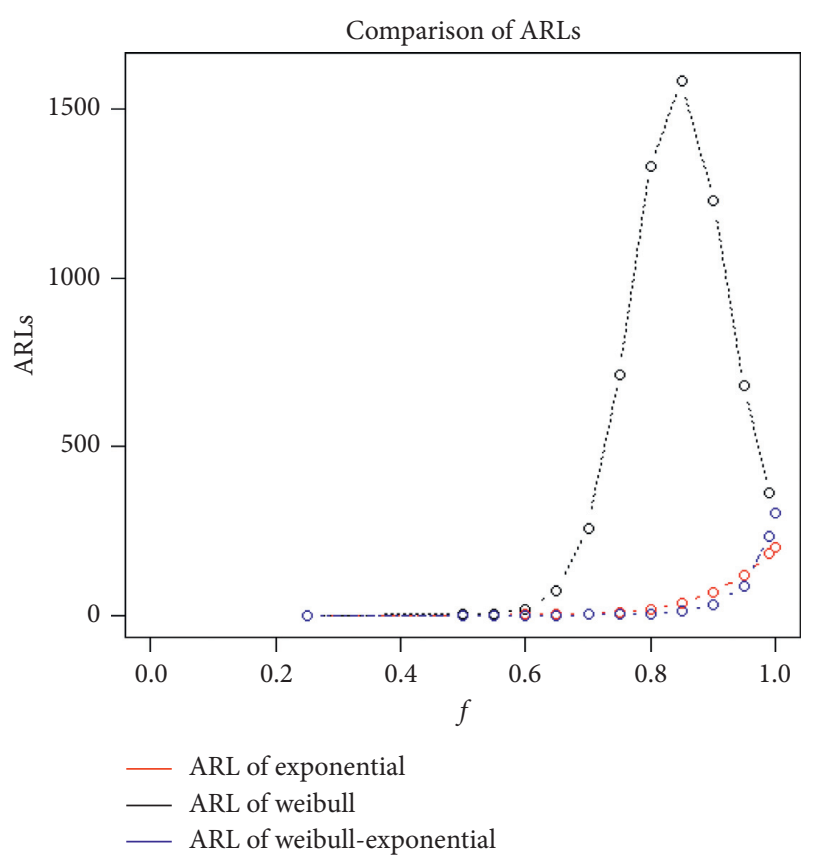

FIGURE 5: ARLs of exponential, Weibull, and proposed WEx at 300 with $p_{L}=0.1$ and $p_{U}=0.9$.

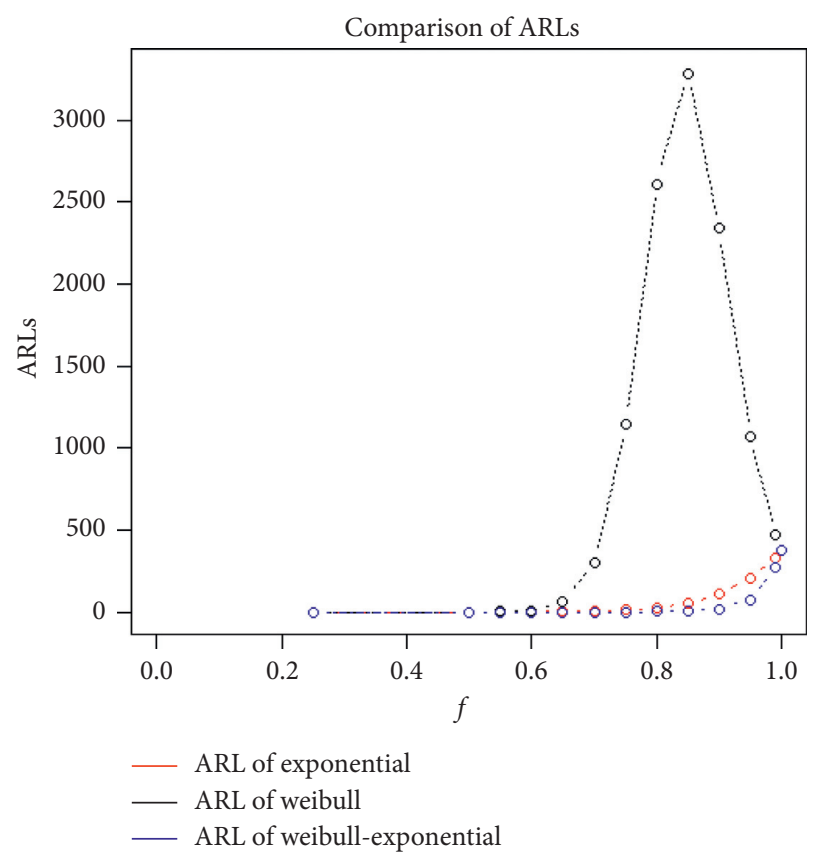

FIGURE 6: ARLs of exponential, Weibull, and proposed WEx at 370 with $\mathbf{P}_{\mathbf{L}}=0.1$ an $\mathbf{d} \mathrm{P}_{\mathrm{U}}=0.9$.

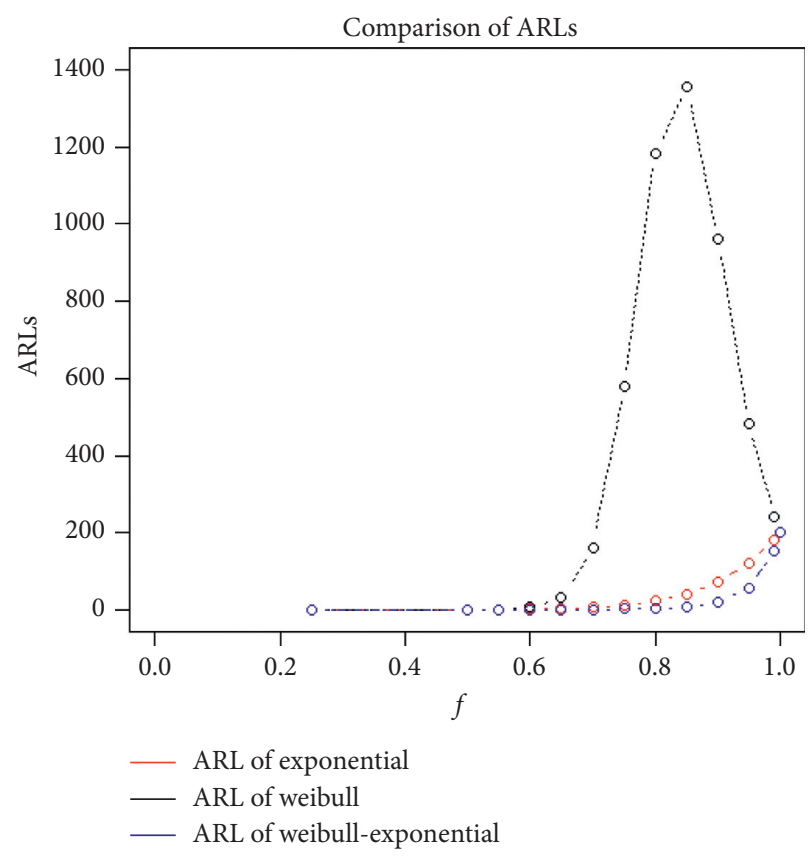

FIgURE 7: ARLs of exponential, Weibull, and proposed WEx at 200 with $p_{L}=0.2$ and $p_{U}=0.8$.

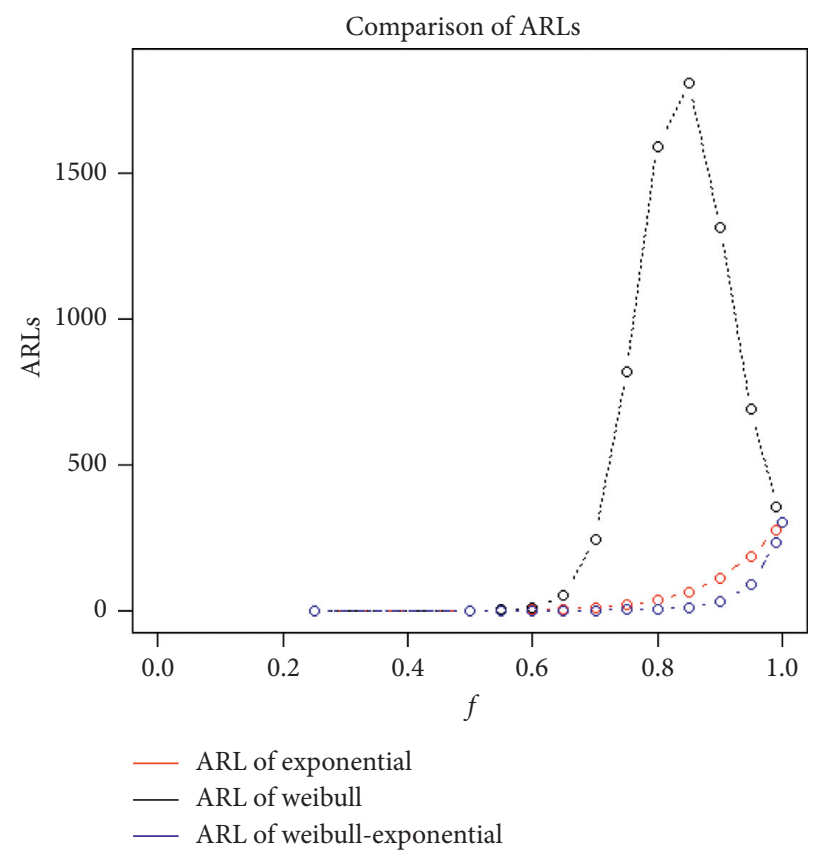

FIgURE 8: ARLs of exponential, Weibull, and proposed WEx at 300 with $p_{L}=0.2$ and $p_{U}=0.8$. 


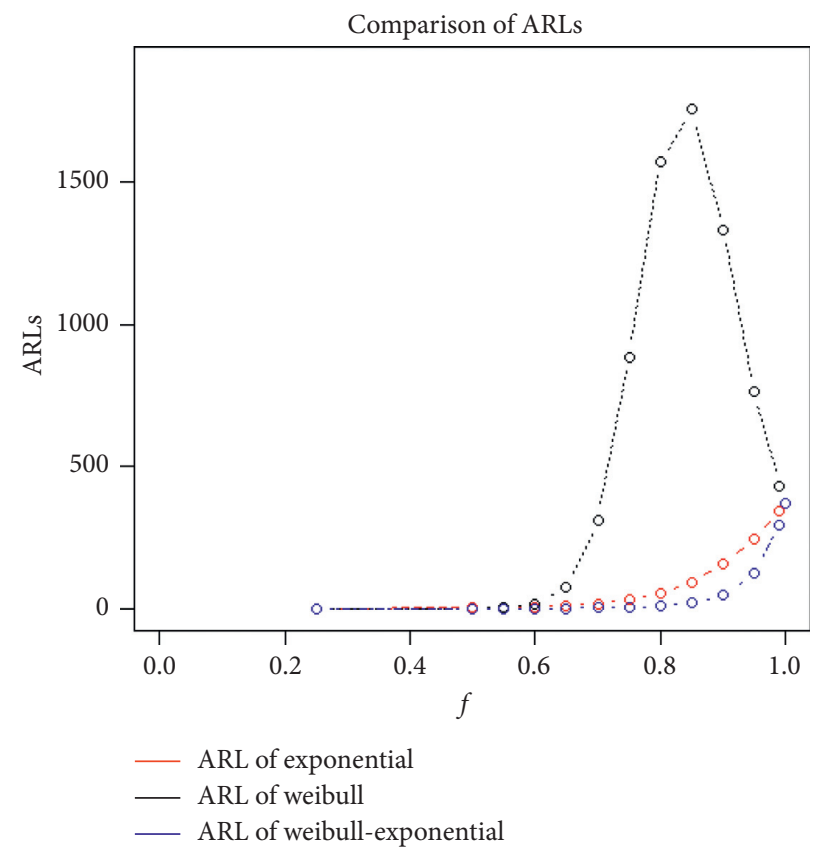

FIgURE 9: ARLs of exponential, Weibull, and proposed WEx at 370 with $\mathbf{p}_{\mathbf{L}}=0.2$ and $\mathbf{p}_{\mathbf{U}}=0.8$.

TABle 6: Simulated in-control data.

\begin{tabular}{|c|c|c|c|c|c|}
\hline 0.220499 & 0.467107 & 0.165884 & 0.478009 & 0.186779 & 0.058493 \\
\hline 0.115906 & 0.088989 & 0.450255 & 0.287988 & 0.867485 & 0.253406 \\
\hline 0.4247 & 0.714495 & 0.356458 & 0.26482 & 0.503415 & 0.529773 \\
\hline 0.278757 & 0.08675 & 0.204802 & 0.181542 & 0.417945 & 0.103082 \\
\hline 0.269525 & 0.543777 & 0.096818 & 0.04666 & 0.070134 & 0.17702 \\
\hline 0.166788 & 0.632749 & 0.482233 & 0.208581 & 0.354741 & 0.242477 \\
\hline 0.592133 & 0.837021 & 0.513781 & 0.086579 & & \\
\hline
\end{tabular}

Table 7: Simulated shifted data.

\begin{tabular}{|c|c|c|c|c|c|}
\hline 0.650604 & 0.144811 & 0.585181 & 0.1867 & 0.613353 & 0.501533 \\
\hline 0.092963 & 0.733554 & 0.192515 & 0.154301 & 0.913754 & 0.573958 \\
\hline 0.462511 & 0.190089 & 0.58542 & 0.297584 & 0.162154 & 0.080671 \\
\hline 0.066036 & 0.746633 & 0.545823 & 0.061 & 0.198106 & 0.92125 \\
\hline 0.057984 & 0.692892 & 0.26246 & 0.463523 & 0.204097 & 0.330734 \\
\hline 0.454024 & 0.765241 & 0.51748 & 0.676308 & 0.341994 & 0.470963 \\
\hline 0.289353 & 0.391563 & 0.502378 & 0.011261 & & \\
\hline
\end{tabular}

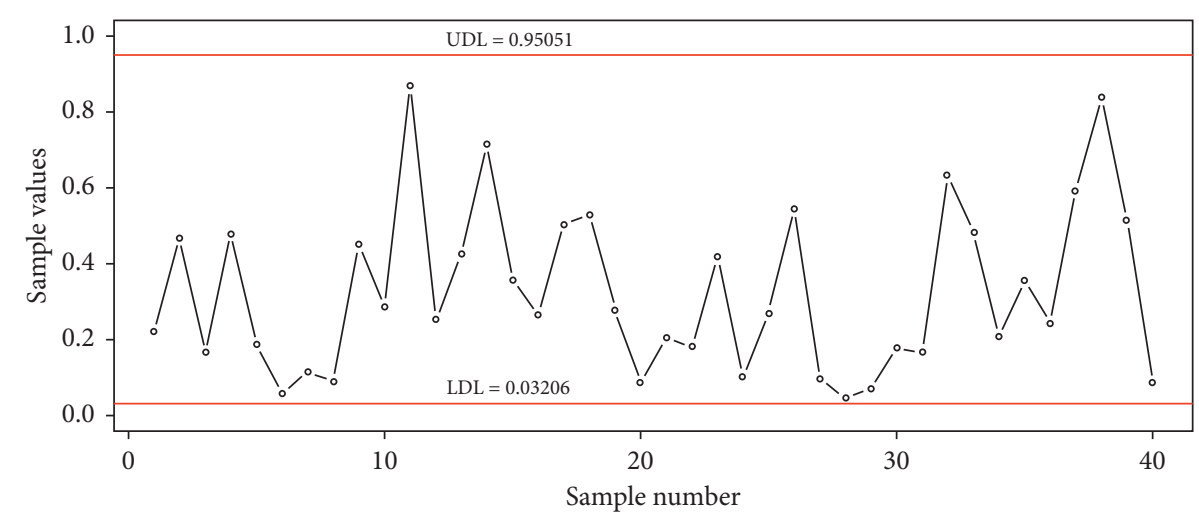

FigURE 10: Plot for simulated in-control data. 


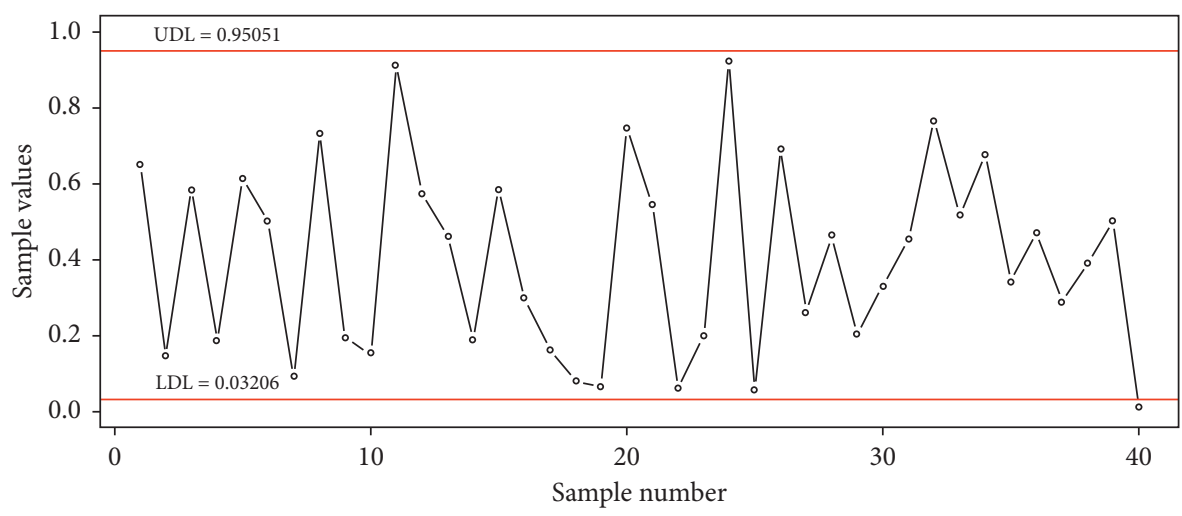

FIgURE 11: Plot for simulated shift data with $f=0.9, p_{L}=0.1, p_{U}=0.9$, and $\mathrm{ARL}_{0}=200$.

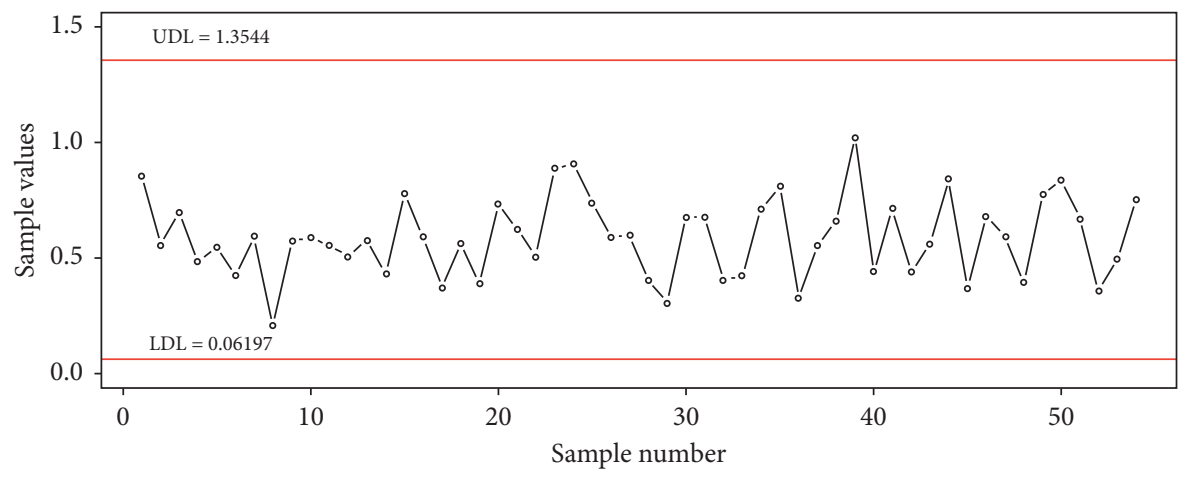

FIgURE 12: Plot of UTI using exponential distribution control chart at $p_{L}=0.1$ and $p_{U}=0.9$.

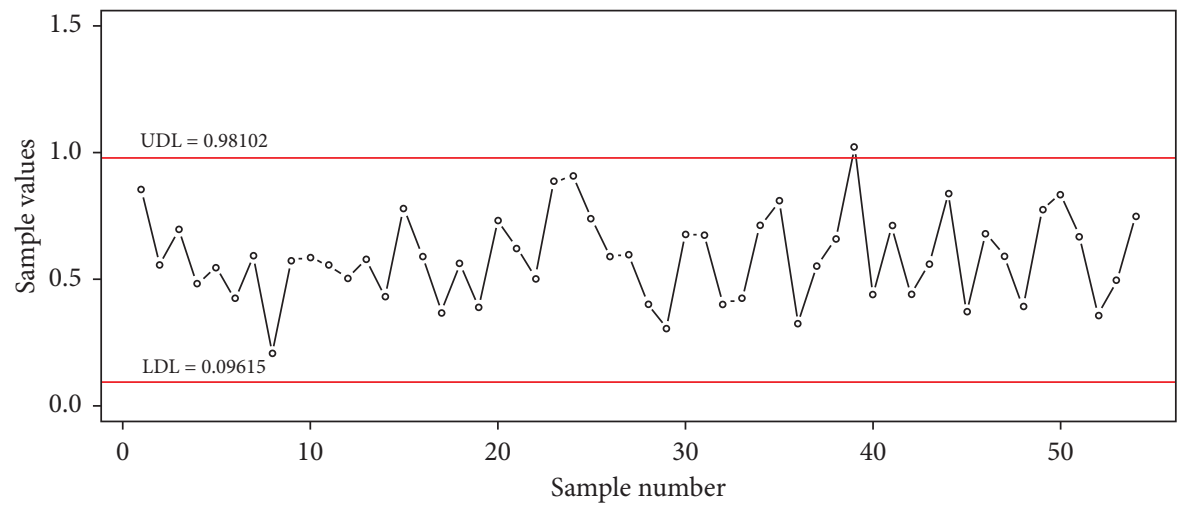

Figure 13: Plot of UTI using proposed (WEx) control chart at $p_{L}=0.1$ and $p_{U}=0.9$.

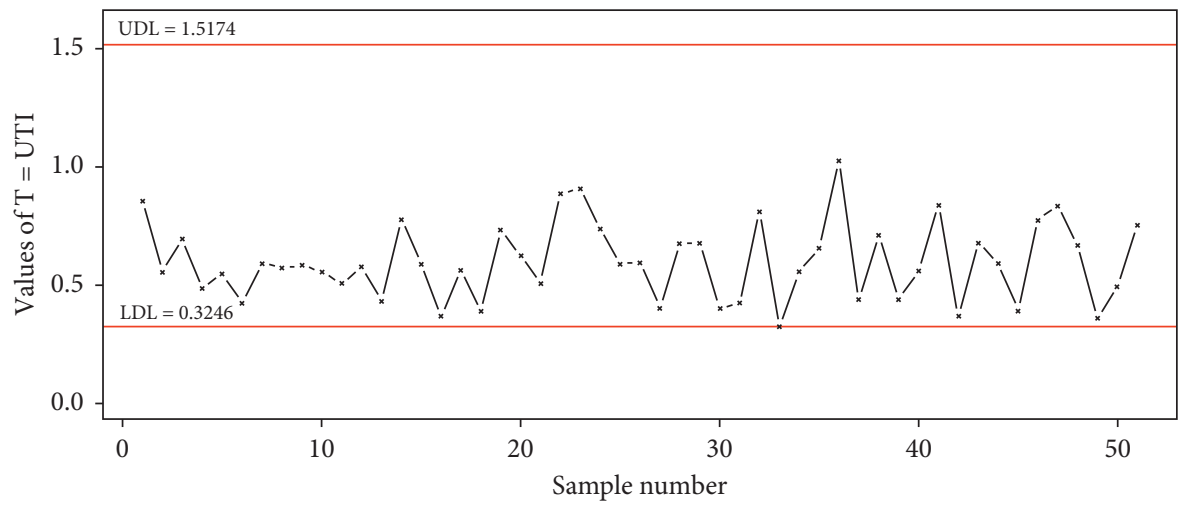

FIgURE 14: Plot of UTI using Weibull distribution control chart at $p_{L}=0.1$ and $p_{U}=0.9$. 
whereas the control chart of the proposed distribution which can be seen in Figure 13 that detected that the process is out-of-control at the 40th value. It may be concluded that our proposed distribution using real data set of UTI shows better performance to detect the out-ofcontrol process quickly.

\section{Conclusion}

In this paper, we develop a new Weibull class of distributions using the distribution generator technique. The newly proposed WEx distribution is applied in the attribute characteristics control chart for monitoring the manufacturing process. Furthermore, we compare the proposed WEx distribution with exponential distribution to monitor the quick detection of the item in the out-of-control process. We conclude that, under various shift levels, our proposed model is more efficient than the exponential distribution. A simulation study is also conducted to known the behavior of ARL using the proposed WEx, Weibull, and exponential distributions. The implementation of the proposed model in a real-life example from the health care department and the comparison of the two models endorse the scope of WEx distribution. We hope that this proposed control chart can also be used for other accepting sampling schemes and other lifetime models (Figure 14).

\section{Notations}

W: Weibull

WEx: Weibull-exponential

R: $\quad$ Range chart

$S^{2}$ chart: Variance chart

W-G: Weibull-generalized

$P_{L}, P_{U}:$ Percentiles

UDL: $\quad$ Upper discriminant limit

LDL: $\quad$ Lower discriminant limit

a: $\quad$ Accepted item

$b: \quad$ Rejected item

$f: \quad$ Shift level

$\alpha, \gamma, c, \lambda$ : Parameters of Weibull-exponential distribution

ARL: $\quad$ Average run-length

$P_{\text {out }}^{0}: \quad$ Probability of out-of-control process

$P_{\text {out }}^{1}: \quad$ Probability of out-of-control process of shifted process

$P_{0}: \quad$ Probability of rejected item when process is incontrol

$P_{1}: \quad$ Probability of rejected item when process is shifted

UTI: Urinary tract infection.

\section{Appendix}

\section{A. R-Code}

Derivation of Equation (9) (Algorithms 1 and 2)
Input: sample sizes (ss), $P_{L}, P_{U}$, and $r_{0}$

$P_{0}=1-P_{U}+P_{L}$

$a=\operatorname{sample}(1: 70,1, \mathrm{~T}) ; b=\operatorname{sample}(1: 70,1, \mathrm{~T})$

$u=a+\mathrm{b}-1 ; l=a-1 ; n=a+b-1$

Pout $0=\operatorname{sum}($ dbinom $(1: \mathrm{u}, n, p 0))$

ARL0[i] = 1/Pout0

$\mathrm{ARL}_{0}[\mathrm{i}]=1 /$ Pout0; $\left.\mathrm{aa}[\mathrm{i}]=a ; \mathrm{bb}[i]=\mathrm{b} ; \mathrm{nn}[i]=n\right\}$

Impose condition $\mathrm{ARL}_{0} \geq r_{0}$

Output: obtain corresponding values of $a, b, n$, and $\mathrm{ARL}_{0}$

Algorithm 1: Computation of $a, b, n$, and $\mathrm{ARL}_{0}$.

Input: different values of shift $(f)$

$f 1=\log \left(1 /\left(1-p_{U}\right)\right) ; f 2=\log \left(1 /\left(1-p_{L}\right)\right)$

$p 1=1+\exp (-f 1 * f)-\exp (-f 2 * f)$

$\mathrm{u}=a+b-1 ; l=a-1$

beta $=\operatorname{sum}(\operatorname{dbinom}(l: u, n, p 1))$

$\mathrm{ARL}_{1}=1 /$ beta; $\mathrm{SDRL}=\operatorname{sqrt}((1-$ beta $) /($ beta $\left.) 2)\right)$

Output: ARL for different values of shift.

Algorithm 2: Computation of ARL for different shifts.

$$
\begin{aligned}
P_{r}\left(X<\mathrm{LCL} \mid c_{0}\right) & =P_{L} \\
1-\exp \left(-\left(\frac{\alpha \lambda x}{\gamma}\right)^{c}\right) & =P_{L} \\
1-P_{L} & =\exp \left(-\left(\frac{\alpha \lambda x}{\gamma}\right)^{c}\right) .
\end{aligned}
$$

Taking $\ln$ on both sides,

$$
\begin{aligned}
\ln \left(1-P_{L}\right) & =\ln \exp \left(-\left(\frac{\alpha \lambda x}{\gamma}\right)^{c}\right) \\
-\ln \left(1-P_{L}\right) & =\left(\frac{\alpha \lambda x}{\gamma}\right)^{c} \\
{\left[-\ln \left(1-P_{L}\right)\right]^{(1 / c)} } & =\left(\frac{\alpha \lambda x}{\gamma}\right) \\
{\left[\ln \left(\frac{1}{1-P_{L}}\right)\right]^{(1 / c)} } & =\left(\frac{\alpha \lambda x}{\gamma}\right) \\
\frac{\gamma}{\alpha \lambda}\left[\ln \left(\frac{1}{1-P_{L}}\right)\right]^{(1 / c)} & =x .
\end{aligned}
$$

The LCL is $(\gamma / \alpha \lambda)\left[\ln \left(1 / 1-P_{L}\right)\right]^{(1 / c)}$. 
Derivation of Equation (10)

$$
\begin{aligned}
P_{r}\left(X<\mathrm{UCL} \mid c_{0}\right) & =P_{U}, \\
1-\exp \left(-\left(\frac{\alpha \lambda x}{\gamma}\right)^{c}\right) & =P_{U}, \\
1-P_{U} & =\exp \left(-\left(\frac{\alpha \lambda x}{\gamma}\right)^{c}\right) .
\end{aligned}
$$

Taking $\ln$ on both sides,

$$
\begin{aligned}
\ln \left(1-P_{U}\right) & =\ln \exp \left(-\left(\frac{\alpha \lambda x}{\gamma}\right)^{c}\right) \\
-\ln \left(1-P_{U}\right) & =\left(\frac{\alpha \lambda x}{\gamma}\right)^{c} \\
{\left[-\ln \left(1-P_{u}\right)\right]^{(1 / c)} } & =\left(\frac{\alpha \lambda x}{\gamma}\right) \\
{\left[\ln \left(\frac{1}{1-P_{U}}\right)\right]^{(1 / c)} } & =\left(\frac{\alpha \lambda x}{\gamma}\right) \\
\frac{\gamma}{\alpha \lambda}\left[\ln \left(\frac{1}{1-P_{U}}\right)\right]^{(1 / c)} & =x .
\end{aligned}
$$

The UCL is $(\gamma / \alpha \lambda)\left[\ln \left(1 / 1-P_{L}\right)\right]^{(1 / c)}$.

Equation (12) Derivation

For the in-control process, the probability of the out-ofcontrol process is demonstrated through control charts is given as

$$
P_{\text {out }}^{0}=1-\sum_{x=a}^{a+b-1}\left(\begin{array}{c}
x-1 \\
a-1
\end{array}\right) P_{o}^{a}\left(1-P_{0}\right)^{x-a} .
$$

The authors compute the probability of out-of-control process as $P(X \geq b)$.

Now,

$$
P(X \geq b)=1-P(X<b) .
$$

Since " $X$ " follows the negative binomial distribution, then

$$
P(X<b)=\sum_{x=a}^{a+b-1}\left(\begin{array}{c}
x-1 \\
a-1
\end{array}\right) p_{0}^{a}\left(1-p_{0}\right)^{x-a} .
$$

Equation (14) Derivation

The probability that the process is found out-of-control due to the shifted process using control chart is obtained as

$$
P_{\text {out }}^{1}=1-\sum_{x=a}^{a+b-1}\left(\begin{array}{c}
x-1 \\
a-1
\end{array}\right) P_{1}^{a}\left(1-P_{1}\right)^{x-a} .
$$

The authors compute the probability of out-of-control process as $P(X \geq b)$.
Now,

$$
P(X \geq b)=1-P(X<b) .
$$

Since " $X$ " follows the negative binomial distribution, then

$$
P(X<b)=\sum_{x=a}^{a+b-1}\left(\begin{array}{c}
x-1 \\
a-1
\end{array}\right) p_{1}^{a}\left(1-p_{1}\right)^{x-a} .
$$

\section{Data Availability}

The data used to support the findings of this study are given in the paper.

\section{Disclosure}

No funds were obtained for this paper.

\section{Conflicts of Interest}

The authors declare that there are no conflicts of interest.

\section{References}

[1] N. Eugene, C. Lee, and F. Famoye, "Beta-normal distribution and its applications," Communications in Statistics-Theory and Methods, vol. 31, no. 4, pp. 497-512, 2002.

[2] S. Nadarajah and S. Kotz, "The beta Gumbel distribution," Mathematical Problems in Engineering, vol. 2004, no. 4, pp. 323-332, 2004.

[3] S. Nadarajah and A. K. Gupta, "The beta Fréchet distribution," Far East Journal of Theoretical Statistics, vol. 14, no. 1, pp. 15-24, 2004.

[4] S. Nadarajah and S. Kotz, "The beta exponential distribution," Reliability Engineering \& System Safety, vol. 91, no. 6, pp. 689-697, 2006.

[5] S. Nadarajah, G. M. Cordeiro, and E. M. M. Ortega, "The zografos-balakrishnan-GFamily of distributions: mathematical properties and applications," Communications in Statistics - Theory and Methods, vol. 44, no. 1, pp. 186-215, 2015.

[6] A. Alzaatreh, C. Lee, and F. Famoye, "A new method for generating families of continuous distributions," Metron, vol. 71, no. 1, pp. 63-79, 2013.

[7] G. M. Cordeiro, E. M. M. Ortega, B. V. Popović, and R. R. Pescim, "The Lomax generator of distributions: properties, minification process and regression model," Applied Mathematics and Computation, vol. 247, pp. 465-486, 2014.

[8] A. Z. Afify, M. Alizadeh, H. M. Yousof, G. Aryal, and M. Ahmad, "The transmuted geometric-g family OF distributions: THEORY and applications," Pakistan Journal of Statistics, vol. 32, no. 2, pp. 139-160, 2016.

[9] M. Alizadeh, M. H. Tahir, G. M. Cordeiro, M. Mansoor, M. Zubair, and G. G. Hamedani, "The Kumaraswamy Marshal-Olkin family of distributions," Journal of the Egyptian Mathematical Society, vol. 23, no. 3, pp. 546-557, 2015.

[10] A. Z. Afify, G. M. Cordeiro, H. M. Yousof, A. Alzaatreh, and Z. M. Nofal, "The Kumaraswamy transmuted-G family of distributions: properties and applications," Journal of Data Science, vol. 14, no. 2, pp. 245-270, 2016.

[11] Z. M. Nofal, A. Z. Afify, H. M. Yousof, and G. M. Cordeiro, "The generalized transmuted-G family of distributions," 
Communications in Statistics-Theory and Methods, vol. 46, no. 8, pp. 4119-4136, 2017.

[12] M. Chahkandi and M. Ganjali, "On some lifetime distributions with decreasing failure rate," Computational Statistics and Data Analysis, vol. 53, no. 12, pp. 4433-4440, 2009.

[13] W. Barreto-Souza, A. H. S. Santos, and G. M. Cordeiro, "The beta generalized exponential distribution," Journal of Statistical Computation and Simulation, vol. 80, no. 2, pp. 159-172, 2010.

[14] W. Lu and D. Shi, "A new compounding life distribution: the Weibull-Poisson distribution," Journal of Applied Statistics, vol. 39, no. 1, pp. 21-38, 2012.

[15] D. C. Montgomery, Statistical Quality Control, Vol. 7, Wiley, New York, NY, USA, 2009.

[16] W. H. Woodall, "The use of control charts in health-care and public-health surveillance," Journal of Quality Technology, vol. 38, no. 2, pp. 89-104, 2006.

[17] S.-L. Hwang, J.-T. Lin, G.-F. Liang, Y.-J. Yau, T.-C. Yenn, and C.-C. Hsu, "Application control chart concepts of designing a pre-alarm system in the nuclear power plant control room," Nuclear Engineering and Design, vol. 238, no. 12, pp. 35223527, 2008.

[18] Z. Wang and R. Liang, "Discuss on applying SPC to quality management in university education," in Proceedings of the 9th International Conference for Young Computer Scientists, pp. 2372-2375, Hunan, China, November 2008.

[19] M. Pastell and H. Madsen, "Application of CUSUM charts to detect lameness in a milking robot," Expert Systems with Applications, vol. 35, no. 4, pp. 2032-2040, 2008.

[20] A. Ivanova, C. Xiao, and Y. Tymofyeyev, "Two-stage designs for phase 2 dose-finding trials," Statistics in Medicine, vol. 31, no. 24, pp. 2872-2881, 2012.

[21] S. W. Roberts, "Control chart tests based on geometric moving averages," Technometrics, vol. 1, no. 3, pp. 239-250, 1959.

[22] D. Brook and D. A. Evans, "An approach to the probability distribution of CUSUM run length," Biometrika, vol. 59, no. 3 , pp. 539-549, 1972.

[23] J. M. Lucas, "Combined Shewhart-CUSUM quality control schemes," Journal of Quality Technology, vol. 14, no. 2, pp. 51-59, 1982.

[24] C. M. Borror, J. B. Keats, and D. C. Montgomery, "Robustness of the time between events CUSUM," International Journal of Production Research, vol. 41, no. 15, pp. 3435-3444, 2003.

[25] M. B. C. Khoo, "A moving average control chart for monitoring the fraction non-conforming," Quality and Reliability Engineering International, vol. 20, no. 6, pp. 617-635, 2004.

[26] S. Sukparungsee and A. A. Novikov, "Analytical approximations for detection of a change-point in case of light-tailed distributions," Journal of Quality Measurement and Analysis, vol. 4, no. 2, pp. 49-56, 2008.

[27] Y. Areepong and A. A. Novikov, "Martingale approach to EWMA control chart for changes in Exponential distribution," Journal of Quality Measurement and Analysis, vol. 4, pp. 197-203, 2008.

[28] R. Noorossana, A. A. Fatahi, P. Dokouhaki, and M. Babakhani, "ZIB-EWMA control chart for monitoring rare health events," Journal of Mechanics in Medicine and Biology, vol. 11, no. 04, pp. 881-895, 2011.

[29] E. Santiago and J. Smith, "Control charts based on the exponential distribution: adapting runs rules for the tChart," Quality Engineering, vol. 25, no. 2, pp. 85-96, 2013.
[30] L. L. Ho and R. C. Quinino, "An attribute control chart for monitoring the variability of a process," International Journal of Production Economics, vol. 145, no. 1, pp. 263-267, 2013.

[31] M. Aslam, M. Azam, and C.-H. Jun, “Acceptance sampling plans for multi-stage process based on time-truncated test for Weibull distribution," The International Journal of Advanced Manufacturing Technology, vol. 79, no. 9-12, pp. 1779-1785, 2015.

[32] A. C. Rakitzis and P. Castagliola, "The effect of parameter estimation on the performance of one-sided Shewhart control charts for zero-inflated processes," Communications in Statistics - Theory and Methods, vol. 45, no. 14, pp. 4194-4214, 2016.

[33] M. Azam, M. N. Aslam, and C.-H. Jun, "An EWMA control chart for the exponential distribution using repetitive sampling plan," 2017.

[34] M. Azam, L. Ahmad, M. Aslam, and C.-H. Jun, "An attribute control chart using discriminant limits for monitoring process under the Weibull distribution," Production Engineering, vol. 12, no. 5, pp. 659-665, 2018.

[35] Z. Wu and J. Jiao, "A control chart for monitoring process mean based on attribute inspection," International Journal of Production Research, vol. 46, no. 15, pp. 4331-4347, 2008.

[36] H. Kim and S. Lee, "On the VSI CUSUM chart for count processes and its implementation with $\mathrm{R}$ package attrCUSUM," Industrial Engineering \& Management Systems, vol. 17, no. 1, pp. 91-101, 2018.

[37] K. Mabude, J. C. Malela-Majika, M. Aslam, Z. L. Chong, and S. C. Shongwe, "Distribution-free composite ShewhartGWMA Mann-Whitney charts for monitoring the process location," Quality and Reliability Engineering International, 2020.

[38] M. T. Shah, M. Azam, M. Aslam, and U. Sherazi, "Time between events control charts for gamma distribution," Quality and Reliability Engineering International, vol. 37, no. 2, pp. 785-803, 2020.

[39] U. Shaheen, M. Azam, and M. Aslam, "A control chart for monitoring the lognormal process variation using repetitive sampling," Quality and Reliability Engineering International, vol. 36, no. 3, pp. 1028-1047, 2020.

[40] M. Aslam, P. Jeyadurga, S. Balamurali, M. Azam, and A. ALMarshadi, "Economic determination of modified multiple dependent state sampling plan under some lifetime distributions," Journal of Mathematics, vol. 2021, Article ID 7470196, , 2021.

[41] R. H. Berk, N. L. Johnson, S. Kotz, and N. Balakrishnan, "Continuous univariate distributions," Technometrics, vol. 2, p. 752, 1996.

[42] C. J. P. Bélisle, "Convergence theorems for a class of simulated annealing algorithms on $\mathbb{R}^{d}$," Journal of Applied Probability, vol. 29, no. 4, pp. 885-895, 1992.

[43] A. Henningsen and O. Toomet, "Maxlik: a package for maximum likelihood estimation in R," Computational Statistics, vol. 26, pp. 443-458, 2011. 